Multi-Megajoule NIF: Ushering In a New Era in High Energy Density Science

C.J. Keane, E. I. Moses

May 2, 2008

SPIE Laser Ablation 2008

Taos, NM, United States

April 21, 2008 through April 24, 2008 
This document was prepared as an account of work sponsored by an agency of the United States government. Neither the United States government nor Lawrence Livermore National Security, LLC, nor any of their employees makes any warranty, expressed or implied, or assumes any legal liability or responsibility for the accuracy, completeness, or usefulness of any information, apparatus, product, or process disclosed, or represents that its use would not infringe privately owned rights. Reference herein to any specific commercial product, process, or service by trade name, trademark, manufacturer, or otherwise does not necessarily constitute or imply its endorsement, recommendation, or favoring by the United States government or Lawrence Livermore National Security, LLC. The views and opinions of authors expressed herein do not necessarily state or reflect those of the United States government or Lawrence Livermore National Security, LLC, and shall not be used for advertising or product endorsement purposes. 


\title{
Multi-Megajoule NIF: \\ Ushering In A New Era in High Energy Density Science
}

\author{
E. Moses \\ Principal Associate Director for National Ignition Facility and Photon Science \\ Lawrence Livermore National Laboratory \\ Livermore, CA 94550 USA
}

\begin{abstract}
This paper describes the status of the stadium-sized National Ignition Facility (NIF), the world's largest laser system and first operational multi-megajoule laser. The 192-beam NIF, located at Lawrence Livermore National Laboratory (LLNL), is 96\% complete and scheduled for completion in March 2009. The NIF laser will produce nanosecond laser pulses with energies up to approximately $4 \mathrm{MJ}$ in the infrared (laser wavelength $=1.053-\mu \mathrm{m}$ ) and $2 \mathrm{MJ}$ in the ultraviolet (laser wavelength $=0.35-\mu \mathrm{m}$ ). With these energies NIF will access conditions of pressure and temperature not previously available on earth, allowing it to conduct experiments in support of the nation's national security, energy, and fundamental science goals. First ignition experiments at NIF are scheduled for FY2010. This paper will provide an overview of the NIF laser and the ignition, energy, and fundamental science activities at NIF.
\end{abstract}

Keywords: National Ignition Facility (NIF), Photon Science (PS), Lawrence Livermore National Laboratory (LLNL), Inertial Confinement Fusion (ICF) emission

\section{INTRODUCTION}

The search for fusion energy is one of the outstanding scientific challenges of the past fifty years. The possibility of achieving controlled fusion burn, or ignition, in the laboratory via the compression of matter to extreme densities is known as inertial confinement fusion (ICF) and has been pursued since the early 1970s. A series of lasers of increasing energy, power, and sophistication have been constructed worldwide in pursuit of the ICF ignition goal.

The culmination of these efforts in the US is the National Ignition Facility (NIF), located at the Lawrence Livermore National Laboratory (LLNL) in Livermore, CA. ${ }^{1}$ (A similar laser known as Le Laser Mégajoule (LMJ) ${ }^{2}$ is being constructed by the Commissariat à l'Énergie Atomique (CEA) near Bordeaux, France.) NIF, a 192-beam Nd-glass laser facility, will produce $1.8 \mathrm{MJ}$ and $500 \mathrm{TW}$ of laser power in the ultraviolet, making it over fifty times more energetic than present ICF facilities. NIF is capable of delivering this energy to a fusion target with the high spatial and temporal precision required to demonstrate ignition. First ignition experiments are scheduled to begin at NIF in FY2010 via a national effort known as the National Ignition Campaign (NIC). ${ }^{3}$

The demonstration of ignition in the laboratory is a key component of the U.S. Stockpile Stewardship Program (SSP), the U.S. National Nuclear Security Administration (NNSA) program that ensures a safe, secure, and reliable nuclear stockpile via a combination of advanced computational simulations and above-ground experiments. Ignition experiments at NIF will also enable inertial fusion as a source of clean energy. More broadly, NIF will advance fundamental science via its ability to create extreme conditions of pressure and temperature in the laboratory.

The NIF is the central facility in the U.S. ICF and High Yield Campaign, which executes ignition and other high-energydensity science experiments in support of the SSP. Major participants in the ICF Campaign include Lawrence Livermore, Los Alamos, and Sandia National Laboratories, the University of Rochester Laboratory for Laser Energetics (LLE), General Atomics, Inc. (GA), and the Naval Research Laboratory (NRL). Other major facilities in the Program include the OMEGA laser at LLE and the $\mathrm{Z}$ machine at Sandia National Laboratories. 
The remainder of this paper discusses the NIF laser, the National Ignition Campaign, implications of NIF ignition for inertial fusion energy, and fundamental high-energy-density science at NIF.

\subsection{OVERVIEW}

\section{NATIONAL IGNITION FACILITY}

The NIF Project was conceived in the early 1990s and formally started in 1995. Ground was broken for NIF on May 27, 1997. Figure 1 identifies the major elements of the facility, including the laser bays, where the 192 infrared laser beams of NIF are located; the switchyard, where the 192 beams are routed to the target chamber area; the experimental area itself, where the beams are converted to the ultraviolet and focused on a target located at the center of a 10-meterdiameter vacuum chamber; the Diagnostics Building, which supports operation and information technology requirements for the NIF diagnostic suite; and the Optics Assembly Building (OAB), where finished NIF optics are assembled into line-replaceable units (LRUs) in preparation for installation in the laser bays and target chamber area.

The NIF building itself is a $350,000 \mathrm{~m}^{3}$ facility that is approximately $150 \times 90 \mathrm{~m}$ in size and seven stories tall. The concrete floor is $2-\mathrm{m}$ thick in the target chamber area and 1-m thick in the laser bays to meet the building vibration and stability specifications required to point the laser on target. The temperature within the laser bays is maintained to \pm 0.3 degrees Celsius to maintain the pointing specification and laser beam quality. Over 2300 vendors participated in constructing NIF. The NIF Project is now 96\% complete overall and will reach project completion in March 2009 at a total cost of approximately $\$ 3.5 \mathrm{~B}$ dollars. Further information on NIF is contained in References $1,4,5$, and references therein.

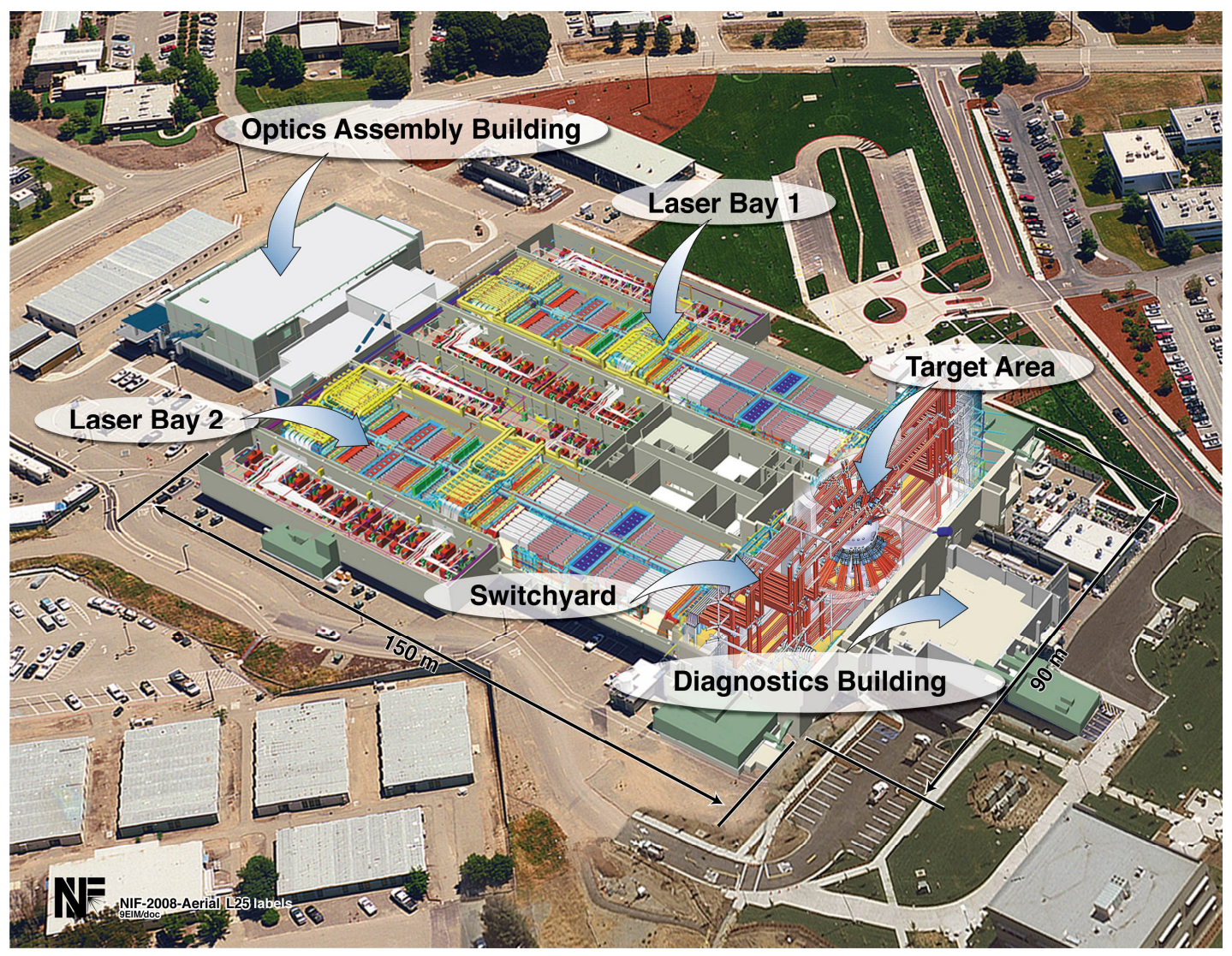

Figure 1: NIF aerial view, showing the two laser bays, switchyard, target chamber area, diagnostics building, and optical assembly building. 
NIF is a highly modular and may be thought of as a conventional facility containing an extensive beampath and target area infrastructure in which modular units know as line-replaceable units (LRUs) containing optics and other required components are installed. The beampath and target area infrastructure are now essentially complete. Approximately 5000 of the 6206 LRUs are installed.

Figure 2 shows a diagram of an individual NIF laser beamline. ${ }^{4}$ The NIF laser pulse starts in a continuous Yb-fiber master oscillator located near the center of the NIF building. The oscillator is split into 48 beams that are precisely temporally shaped via integrated optical circuits. The few nanojoule output from the pulse shapers is injected into 48 preamplifier sections, each of which feeds a single "quad" of 4 laser beams. Each of NIF's two laser bays holds 96 beams, including 24 preamplifier sections. Unlike previous high-energy ICF lasers, NIF employs a multi-pass laser architecture that minimizes the facility size and allows efficient extraction of the energy stored in the Nd-doped phosphate glass amplifiers. For ignition experiments, the 192-beam laser will produce approximately 4 MJ of laser light in a high-contrast, precision shaped pulse at a wavelength of $1.053-\mu \mathrm{m}$. The total amplification of light energy from the master oscillator through the 192 final power amplifiers exceeds $10^{15}$.

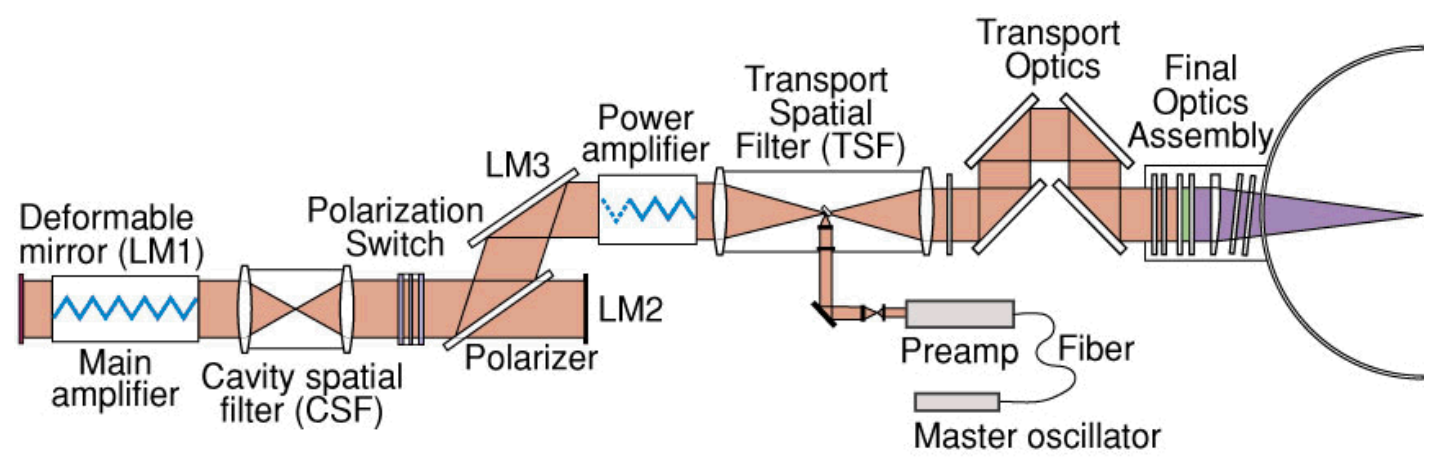

Figure 2: Schematic diagram of an individual NIF laser beamline (192 beamlines total).

Six major technological advances were required to successfully construct the NIF laser. ${ }^{5}$ These include large-aperture plasma Pockels cells switches necessary to allow the beamline to function in a multi-pass mode; deformable mirrors to control the quality of the beam wavefront during successive amplification; mass production of high-quality Nd-laser glass (if placed end-to-end, NIF's 3072 laser slabs would stretch 1.5 miles); 48 separate, synchronized, highly precise pre-amplifiers, each of which amplifies 4 individual beams by a factor of twenty million each with high spatial, temporal, and spectral precision; development of rapid-crystal-growth techniques, which allowed necessary KDP crystals to be grown in months instead of years, thereby allowing the beamlines to be outfitted with crystals in a few years instead of twenty; and the NIF Integrated Controls System, which monitors 60,000 control points and ensures that all 192 beams arrive at the target chamber center at the same time with 30 psec accuracy.

The 264,000-pound NIF target chamber was fabricated in 18 separate pieces, assembled at the NIF site, and lifted into the laser building in 1999. The chamber is covered with $30 \mathrm{~cm}$ of boron-doped concrete to absorb neutrons from the fusion reactions occurring during ignition experiments. The chamber is fabricated from aluminum to reduce neutron activation. Over 100 ports are available for diagnostic instrumentation, target insertion, and other functions.

Approximately 35 sophisticated diagnostics that record the temporal and spatial behavior of $x$-ray, neutron, and other emissions from the target will be fielded at NIF by 2010 in support of initial ignition experiments.

\subsection{NIF OPTICS}

NIF is the largest precision optical instrument ever constructed. NIF requires approximately 8000 large (clear aperture 40 $\times 40 \mathrm{~cm}$ ) optics of 26 different types and 30,000 small optics. A new approach to production manufacturing of highquality optics was used to produce these optics on schedule for the planned cost. This method relied on 
laboratory/vendor partnerships to develop the necessary production processes and production capacities, rather than leaving vendors alone to develop the required capabilities. Figure 3 summarizes the procurement strategy for NIF optics.

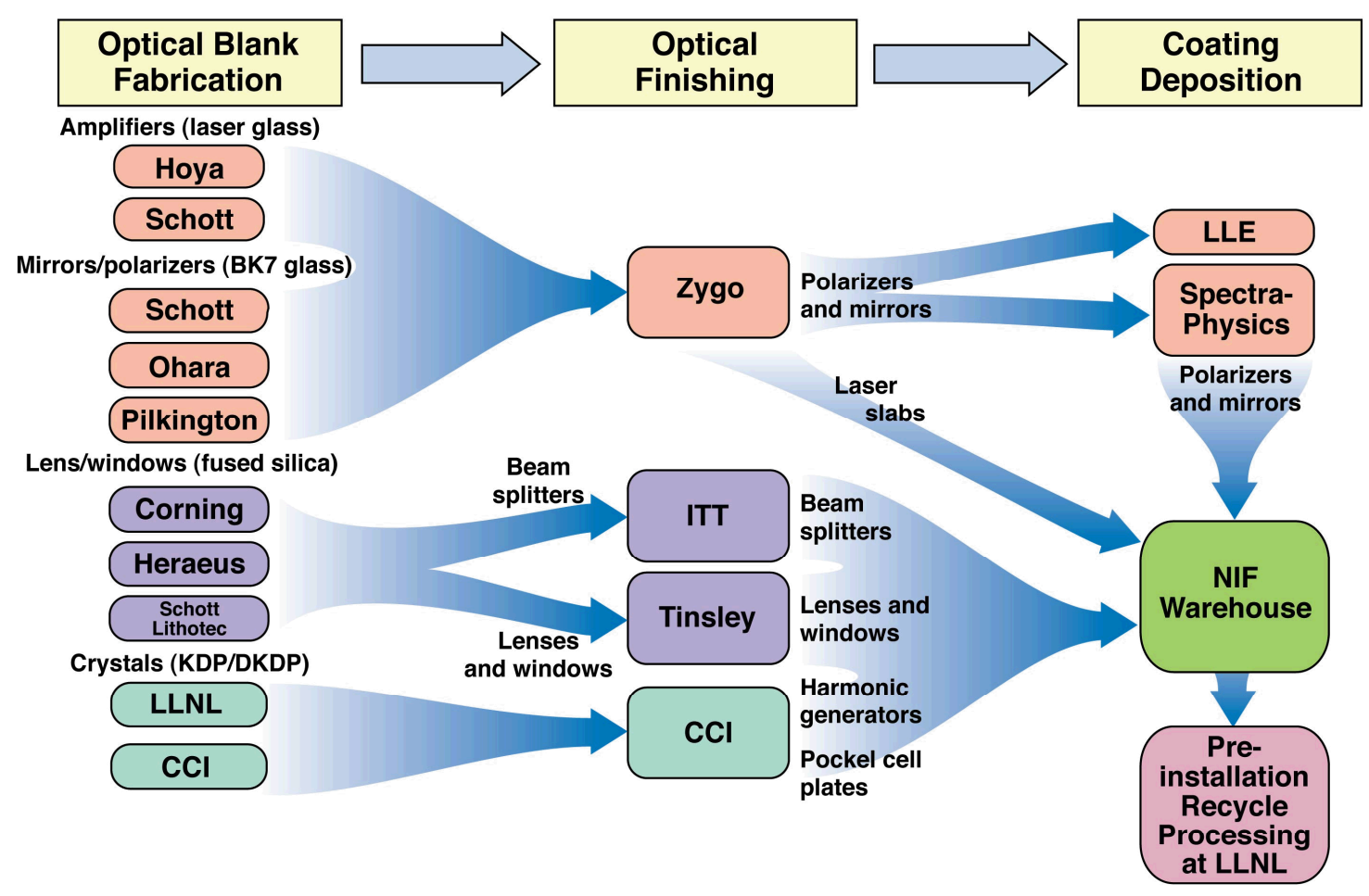

$\underset{18 E I M / d i j}{\text { NIF-0506-12051 }}$

Figure 3: Procurement strategy for NIF optics.

This cooperative approach resulted in delivery of NIF optics that met or exceeded all specifications, on schedule and within budget. A major example of this is the Nd-doped phosphate glass used in the NIF and LMJ laser amplifiers, procured via a joint effort involving Schott, Inc., Hoya Inc., LLNL, and the French Commissariat de L'Energie Atomique (CEA).

Laser glass for previous large lasers at LLNL such as Nova and Shiva was produced at commercial vendors via a one-ata-time batch melting process. Each NIF beamline includes 11 and 5 glass slabs in the main and power amplifiers (see Figure 2), respectively. The resulting large number of laser slabs required $(16 \times 192=3072)$, along with spares and a similar demand for LMJ, could not be produced in a timely or cost effective manner via the traditional batch process. Hence, LLNL and CEA worked closely with Schott Glass Technologies, Inc. and Hoya Corporation USA over a 6-year period to develop a continuous laser glass melting process (Figure 4). This revolutionary process ultimately produced meter-scale laser glass 20 times faster than the previous batch method, with 2 to 3 times the optical quality. The continuous melt process reduced the cost of the glass to less than $\$ 1000 /$ liter compared to the $\$ 5000 /$ liter cost typical of the batch process. NIF/LMJ laser exceeds specifications and is the highest quality Nd-laser glass ever made, and is also in use at OMEGA EP and other laser facilities. 

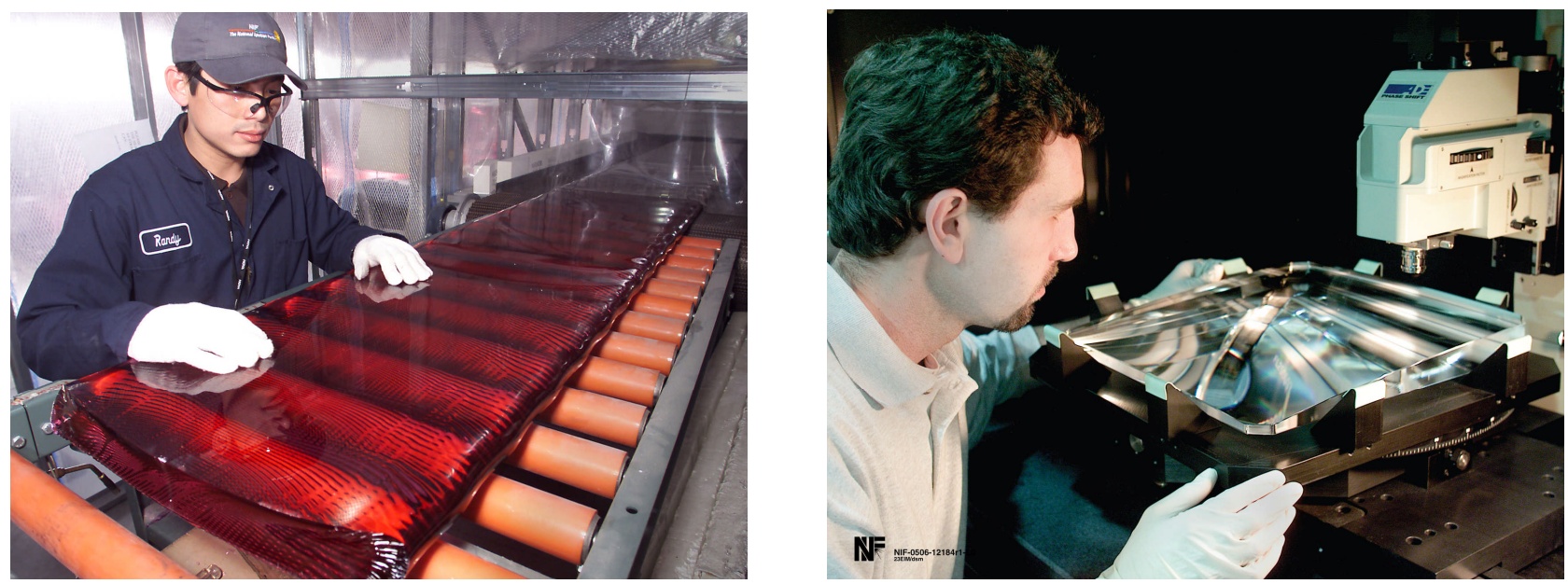

Figure 4 left: NIF laser glass emerging from a continuous glass melter. Right: NIF wedge focus lens.

A similar partnership was made with Cleveland Crystal, Inc. (CCI) for production and finishing of large potassium dihydrogen phosphate (KDP) and deuterated (DKDP) crystals for use in the final focusing system and plasma electrode Pockels cell switch. Over 100 large boules of KDP and DKDP and approximately 600 large slices of crystal from these boules were needed for NIF. Growing these crystals via normal methods would have taken years. A rapid growth method first pioneered in Russia was brought to fruition at LLNL and used to grow the required crystals in just months; a new record $380 \mathrm{~kg}$ KDP crystal boule was grown via this effort. Development of this technique was recognized with an $\mathrm{R}+\mathrm{D}$ 100 Award. LLNL partnered with CCI to produce the required crystals using this rapid growth technique. The facilities installed at CCI include an expanded finishing facility that produces 150 finished crystals per year.
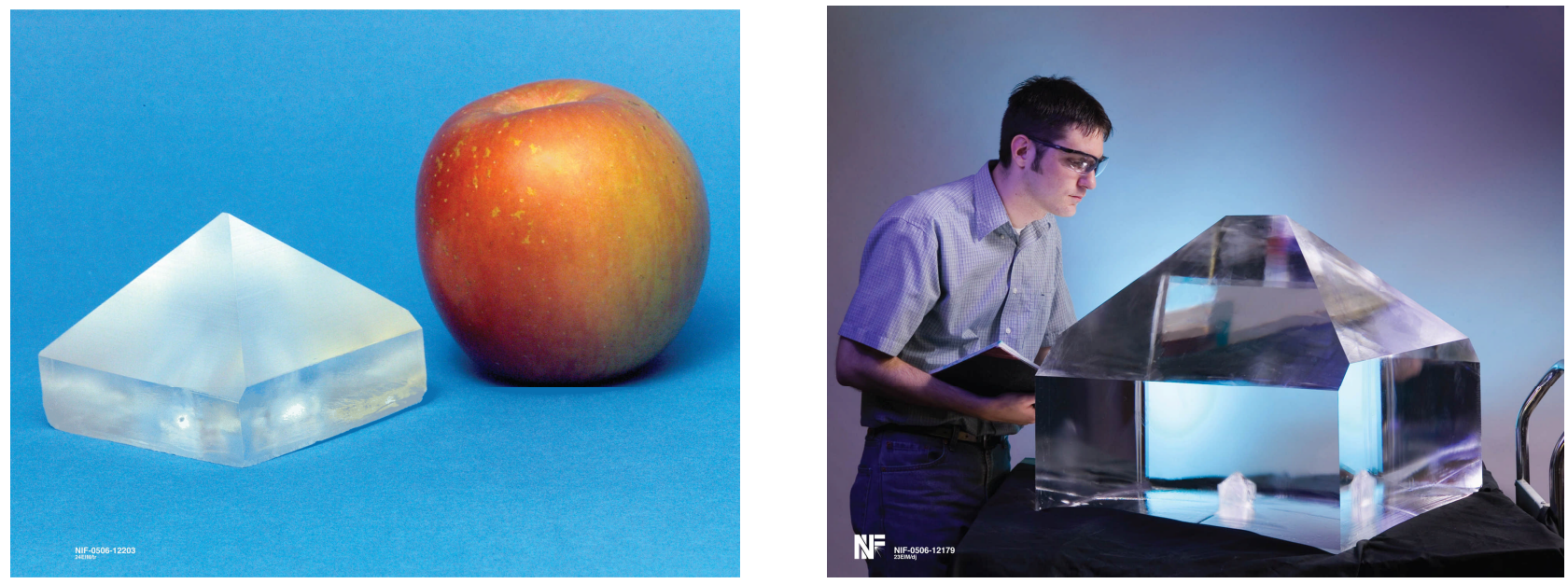

Figure 5 left: KDP crystal grown with mid-1990s technology. Right: NIF KDP crystal grown via rapid-growth technique.

Industrial partnerships were also important for successful fabrication of large fused silica optics such as the final focusing lens shown in Figure 4, right. The NIF Project's cost and schedule goals required a 5 to 10 times increase in large optic production rate from vendors, along with a 3 to 5 times decrease in cost and the ability to operate at a fluence of $8 \mathrm{~J} / \mathrm{cm}^{2}$, approximately 10 times higher than on previous systems such as Nova and OMEGA. These demanding specifications were all met via development of industrial partnerships. This included an LLNL program aimed at elimination the production of damage initiation sites via improvement of the fabrication and finishing process. The result has been the production of large fused silica optics essentially free of subsurface damage. The major example of this success, and the most demanding large optic in NIF, is the NIF wedge final focus lens shown in Figure 4. The wedge 
shape on this 7.7-m focal length reversed plano-convex optic allows four of these final optics to be closely packed in the NIF "quad" focusing geometry and also provides angular dispersion of the unwanted $1.053-\mu \mathrm{m}$ and $0.53-\mu \mathrm{m}$ focused light away from the target. During operation of NIF, optics in the ultraviolet section such as the final focus lens will be continuously inspected for damage and repaired as needed at LLNL using conditioning and mitigation techniques developed within the optical damage research program.

\subsection{NIF LASER PERFORMANCE}

As shown in Figure 2, the individual NIF laser beams are frequency converted to the ultraviolet in the final focusing assembly, which is located on the exterior of the target chamber. The modular nature of the laser allows the infrared section in the laser bays and the ultraviolet section in the target area to be assembled and tested independently.

Outstanding progress has been made in commissioning the infrared section of the laser. Figure 6 indicates that as of April 30, 2008, 19 bundles, or 152 beams, have now been operationally qualified in the infrared. These beams have been qualified one bundle ( 8 beams) at a time, with a total equivalent energy of $3.3 \mathrm{MJ}$. In addition to this bundle-by-bundle qualification, all beams have been successfully fired simultaneously in the infrared at low power. This represents a major accomplishment for the NIF Integrated Computer Control System, which will ultimately control 60,000 points within NIF using 1300 processes and running on 1030 computers. In addition, all amplifier system commissioning has been completed.

Strong progress has also been made in commissioning the ultraviolet section of the laser. The first 4 NIF beamlines were commissioned in the ultraviolet to the target chamber in 2003. Through 2005, over 400 target experiments were conducted using these 4 beams. Following these experiments, target experiments ceased and effort was focused on completion of the infrared section of the laser. Ultraviolet light experiments have recently resumed in the target chamber and the first bundle of 8 beamlines is being commissioned to the center of the target chamber. The NIF Project anticipates 48-beam and 96-beam operation in the ultraviolet to be demonstrated in the next six months.

In addition to these commissioning activities, an extensive series of individual beamline tests have been performed using an extensive array of laser diagnostics known as the Precision Diagnostic System (PDS), located in Switchyard 2, between Laser Bay 2 and the target chamber. PDS supports detailed evaluation of individual beamline performance at $1.053-\mu \mathrm{m}, 0.53-\mu \mathrm{m}$, and $0.35-\mu \mathrm{m}$.

Results from an extensive series of individual beamline tests conducted in 2005 and 2006 are shown in Figure 6. Energies of $25 \mathrm{~kJ}, 17 \mathrm{~kJ}$, and $11 \mathrm{~kJ}$ have been measured at $1.053-\mu \mathrm{m}, 0.53-\mu \mathrm{m}$, and $0.35-\mu \mathrm{m}$ wavelengths, respectively. This is well in excess of the energy required to produce the nominal maximum 192-beam energy of $1.8 \mathrm{MJ}$ in the ultraviolet.
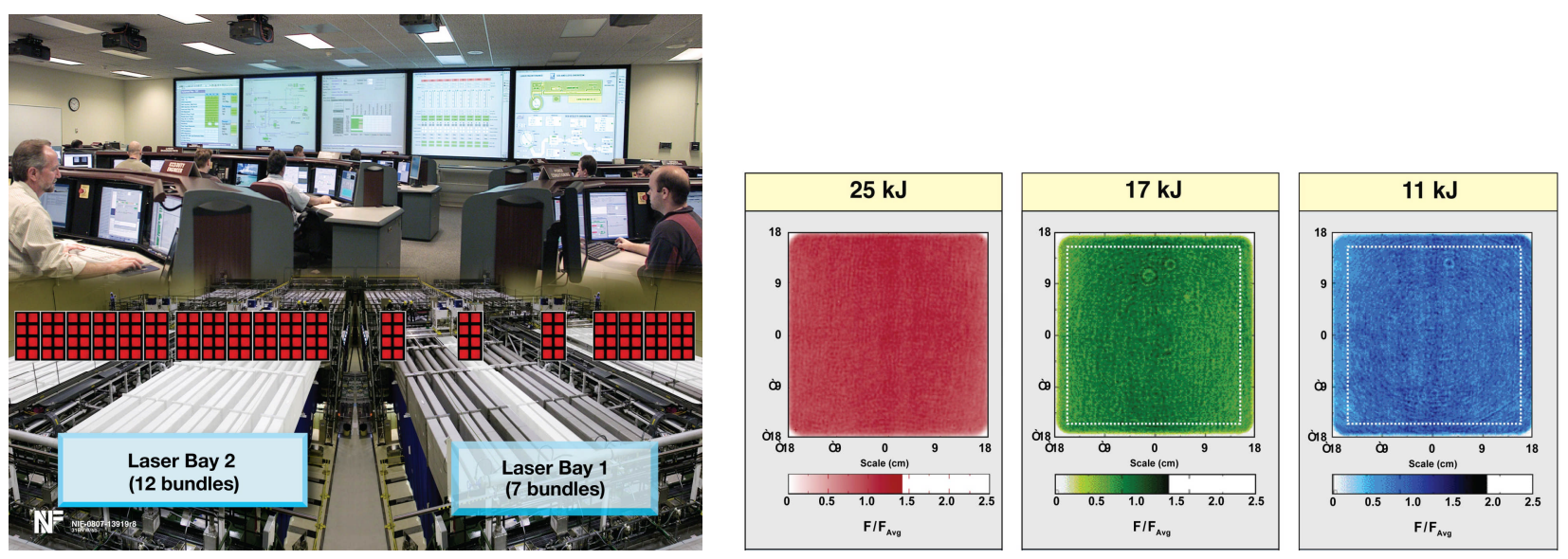

Figure 6 left: Diagram of laser bundles operationally qualified at NIF. A total of 19 bundles (152 beams) were operationally qualified as of April 30, 2008. Right: Full aperture output of a single NIF beamline at 1.053- $\mu \mathrm{m}, 0.53-\mu \mathrm{m}$, and $0.35-\mu \mathrm{m}$. 
To meet ignition requirements, the NIF laser must also meet a demanding set of specifications involving focal spot size and smoothness, bandwidth, dynamic range, and other quantities specified in the NIF Project Primary Criteria and Functional Requirements. These specifications have also been tested using the PDS; examples of these results are shown in Figure 7. NIF ignition targets require a highly shaped pulse to control the arrival time of hydrodynamic shocks at the center of the target; ignition is achieved in the NIF baseline target when several such shocks coalesce at the target center and generate the required "hot spot." Figure 7 (left) shows NIF's ability to tune the shock time arrival by small variations in the amplitude and timing of the laser pulse. Generally, excellent agreement is obtained between measured NIF laser pulse shapes and those predicted by the LPOM (Laser Performance Operations Model). ${ }^{4}$

Focal spot smoothness reduces the effects of laser-plasma instabilities and for this and other reasons is also important for achieving ignition. The NIF laser beams are smoothed using a combination on continuous phase plates, smoothing by spectral dispersion, and polarization smoothing. Figure 7 (right) shows measured vs. calculated single-beamline focal spots at both $1 \mathrm{MJ}$ and $1.8 \mathrm{MJ}$ equivalent energies and essentially demonstrates that NIF beam smoothness meets ignition requirements. ${ }^{4}$
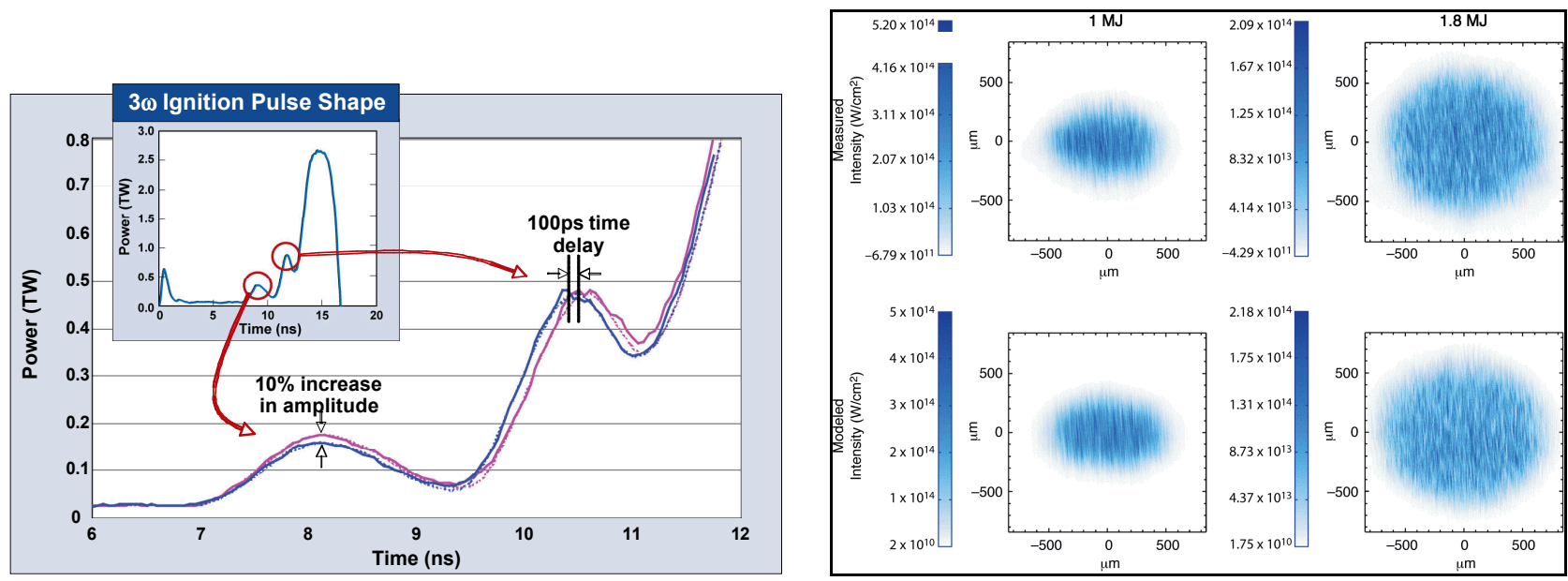

Figure 7 left: NIF ignition pulse (inset) and two separate measured $0.35-\mu \mathrm{m}$ laser pulses with specified amplitude and timing shifts added, demonstrating ability to control laser pulse shape and shock timing. Right: Comparison of measured (top) and calculated (bottom) focal spots with both continuous phase plates (CPP's) and smoothing by spectral dispersion. The images on the left are from a 1-MJ equivalent shot with a $0.50-\times 0.95-\mathrm{mm}$ FWHM spot size CPP. The images on the right are from a 1.8-MJ equivalent shot with a 1.16- $\times 1.3-\mathrm{mm}$ FWHM spot size CPP.

\section{THE NATIONAL IGNITION CAMPAIGN}

The NIF's primary goal is the demonstration of inertial fusion ignition in the laboratory. The ability to examine issues related to ignition and thermonuclear burn in the laboratory is an SSP requirement. The demonstration of ignition will also prove the scientific feasibility of inertial fusion energy (IFE) and open up new frontiers in fundamental high-energydensity science. References 6 and 7 provide further detail regarding the physics of ignition targets.

NIF as constructed will operate in the "indirect-drive" configuration in which the laser beams are directed into either end of a cylinder coated with gold or other high- $Z$ materials mounted vertically within the target chamber. The laser irradiation of the cylinder produces a radiation field inside the cylinder that implodes a mm-scale capsule filled with a mix of deuterium and tritium. Figure 8 shows a schematic of the NIF indirect-drive hohlraum and capsule as well as a picture of an actual hohlraum. The multiple cones of laser beams shown in Figure 8 are used to control the time dependent symmetry of the radiation drive. NIF is also capable of irradiating targets in "direct-drive" mode, where the laser beams irradiate and compress a capsule directly. 

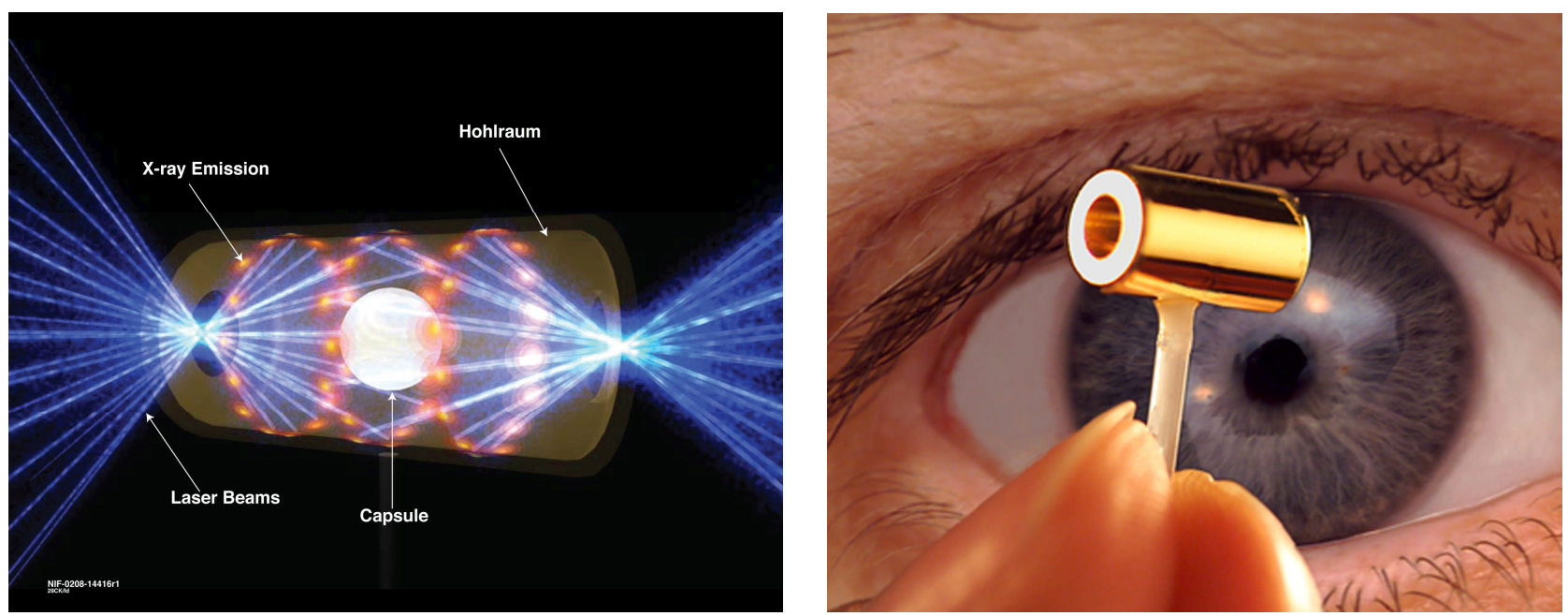

Figure 8 left: Artist drawing of NIF laser beams and ignition target. Right: Actual NIF hohlraum.

Initial NIF ignition experiments will commence by late FY2010 at total 192-beam ultraviolet laser energies of approximately 1.2 MJ. This energy level is consistent with the laser-commissioning plan that ramps up the planned routine 192-beam operating energy of NIF to $1.8 \mathrm{MJ}$ by late 2011. The target design to be used in initial ignition experiments is shown in Figure 9. Two capsule ablator materials (Be with $\mathrm{Cu}$ dopant and $\mathrm{CH}$ with $\mathrm{Ge}$ dopant) are under consideration for initial ignition experiments. Both capsules are filled with DT gas via a $10-\mu \mathrm{m}$-diameter $\mathrm{SiO}_{2}$ fill tube to a density of $0.3 \mathrm{mg} / \mathrm{cm}^{3}$ with a DT solid layer at 18.3 degrees Kelvin. The $\mathrm{Cu}$ and $\mathrm{Ge}$ dopant density is varied through the ablator and is typically present at less than $1 \%$ concentration. Calculated one-dimensional yields for the $\mathrm{CH} / \mathrm{Ge}$ and $\mathrm{Be} / \mathrm{Cu}$ capsules are $16.5 \mathrm{MJ}$ and $21 \mathrm{MJ}$, respectively. Maintaining these two design options reduces risk and allows the choice of a target optimally configured to the precise laser and target fabrication capabilities available.

The NIF ignition program is managed via a multi-laboratory effort known as the National Ignition Campaign (NIC). The major participants in the NIC are the three NNSA weapon laboratories (LLNL, LANL, SNL) as well as the University of Rochester Laboratory for Laser Energetics (LLE) and General Atomics, Inc. (GA). The primary goals of the NIC are to commence ignition experiments by late FY2010 and transition NIF to routine facility operations by the end of FY2012. Figure 9 also shows the schedule for NIF-related activities. Approximately 35 NIF diagnostics will be installed and activated as part of the NIC. This diagnostic suite will include a high-energy petawatt laser (nominally $12 \mathrm{~kJ}$ in a 10-ps pulse), which will provide the ability to radiograph the compressed cores of fusion targets and other high-density materials of interest to stockpile stewardship.
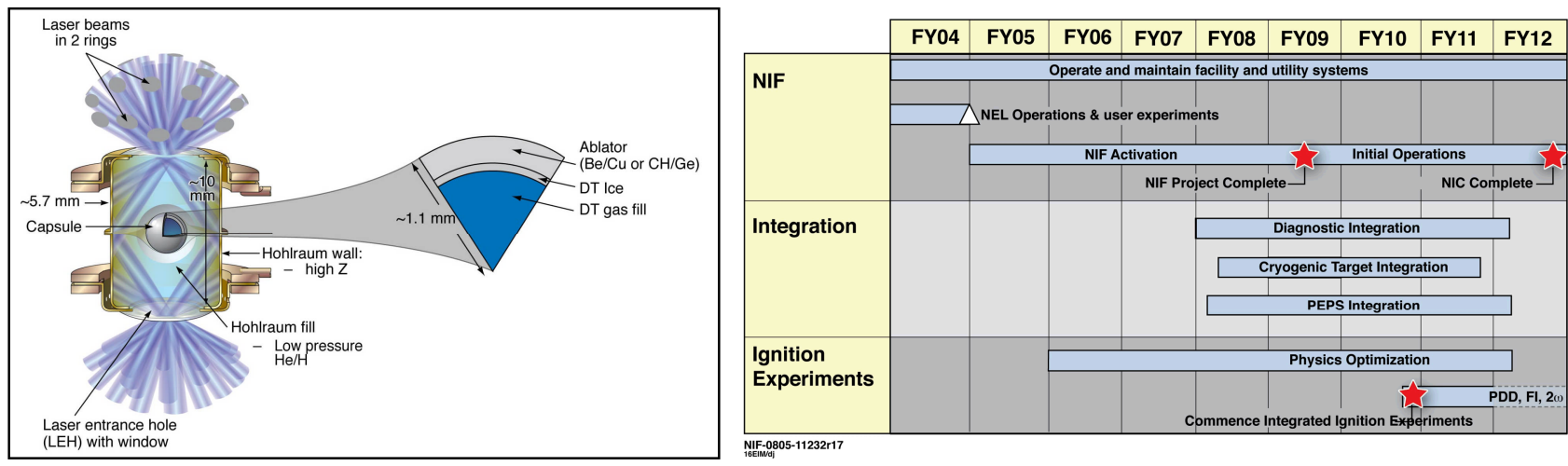

Figure 9 left: NIF ignition target. Right: Schedule for NIF construction and ignition activities. 


\section{INERTIAL FUSION ENERGY AND FUNDAMENTAL SCIENCE AT NIF}

The production of clean, plentiful energy is the major challenge facing mankind in the $21^{\text {st }}$ century. The anticipated growth in demand shown in Figure 10, left, coupled with the potentially ruinous climate effects of fossil fuels, mandate that alternative energy sources be developed. Fusion is one long-term possibility for meeting the world's energy demands; waste is minimal and the fuel (water) is plentiful. Fifty cups of water burned in a fusion energy plant would provide approximately the same energy output as burning two tons of coal.

NIF ignition will demonstrate the scientific feasibility of inertial fusion energy. To bring fusion energy to fruition will also require the development of numerous of new technologies in areas such as lasers, targets, and target chambers. Fusion energy lasers will need to operate at $10 \mathrm{~Hz}$ with electrical efficiencies of $20 \%$ as opposed to the $10^{-4} \mathrm{~Hz}$ and $0.5 \%$ available at NIF. Higher gain targets will be explored on NIF in support of stockpile stewardship and inertial fusion energy goals. As shown in Figure 10, right, the higher laser energy available at $0.53-\mu \mathrm{m}$ wavelength may allow the production of higher gain and yield. In addition, the "fast ignition" scheme shown in Figure 10, right, may produce higher gains. ${ }^{8,9}$ In the fast ignition scheme, a compressed core is formed with a nsec-duration laser and then ignited with the help of high-energy petawatt driver. The fast ignition scheme can reduce the required driver energy significantly.
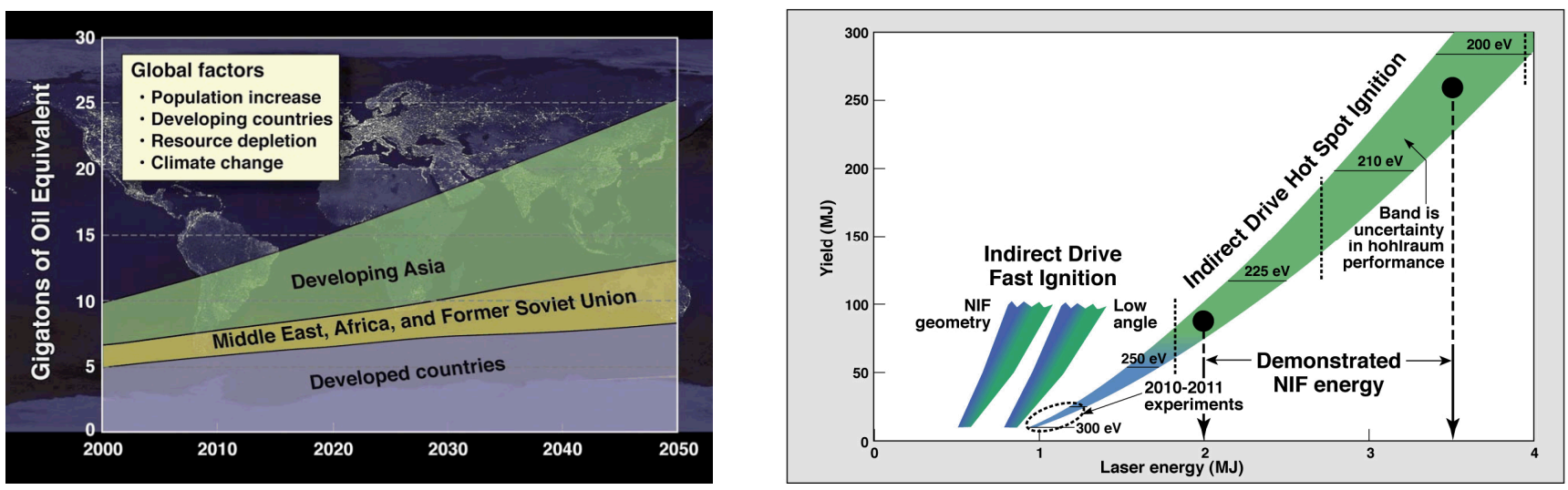

Figure 10 left: Projected world energy demand through 2050. Right: Calculated yields vs. NIF laser energy for indirect drive "hot spot" and "fast ignition" schemes.

The extreme conditions produced in NIF targets $\left(\mathrm{T} \sim 10^{8}\right.$ degrees; $\rho \sim 1000 \mathrm{gm} / \mathrm{cm}^{3}$, pressures greater than $10^{11}$ times atmospheric) will open up entirely new and unexplored scientific frontiers. The study of matter at extreme conditions, known as high energy density science, is evolving rapidly and has been recognized to be of importance in a number of recent federal reports. ${ }^{8-10}$ NIF will be the premier facility in the world for some time for the study of fundamental highenergy density science. Figure 11, left, shows some examples of the scientific questions accessible at NIF. NIF experiments can look at a variety of questions related to stellar evolution, including possible definition of the mechanism by which supernovae explode and development of understanding of accretion disks, the photoionized plasmas produced when material is accreted near a black hole or active galactic nuclei. NIF experiments investigating the behavior of matter at extreme pressures may also shed light on whether the interior of Jupiter is ice or rock, see Figure 11, right. Further information on the scientific opportunities at NIF is available in Ref. 5 and the references contained therein. 

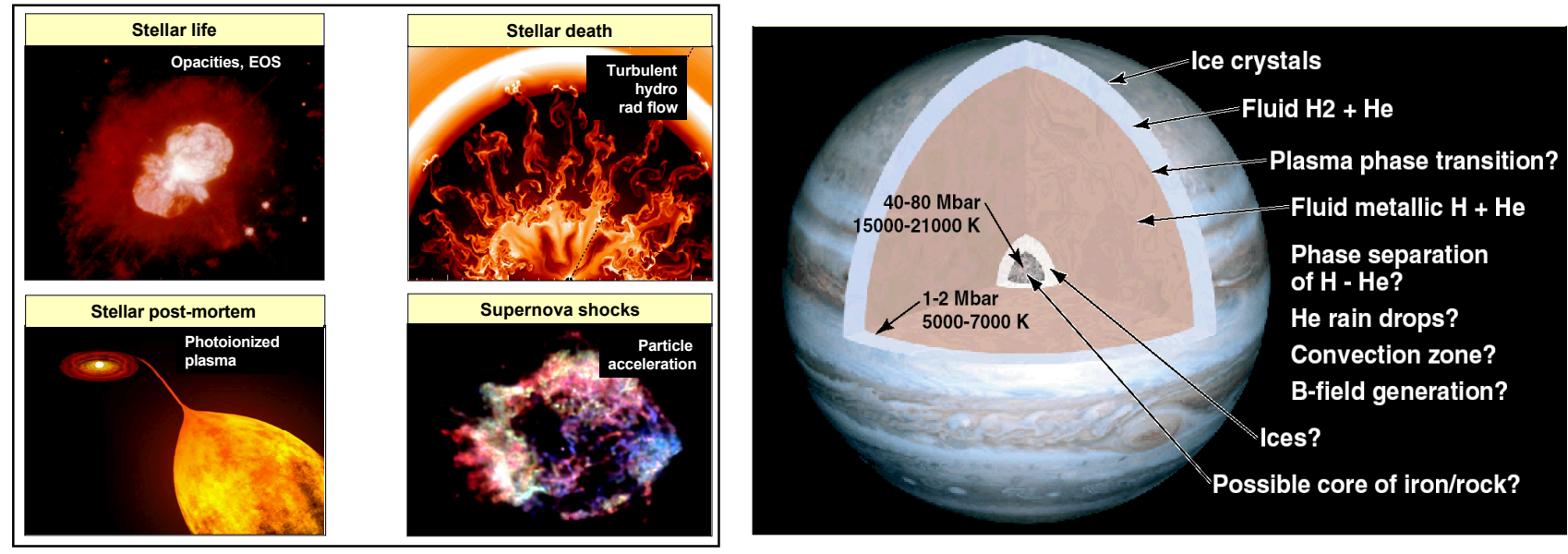

Figure 11 left: Stellar life cycle components and specific issues to be addressed via NIF experiments. Right: Diagram of Jupiter showing key features and unresolved issues; NIF can produce pressures in excess of those in Jupiter's interior.

\section{CONCLUSION}

The 192-beam NIF is the world's first operational megajoule laser and one of the largest projects ever undertaken by the U.S. Department of Energy. The construction of NIF was made possible by the dedicated efforts of thousands of people at LLNL and elsewhere, including industrial partners who worked closely with LLNL staff to develop the required optics and supporting infrastructure for the laser. NIF has already demonstrated full, required performance at the individual beamline level, and the control system crucial to 192-beam operation has also been tested and validated. The Project is now $96 \%$ complete. Optics and other equipment are now being installed in preparation for ignition experiments, which are scheduled to start by the end of FY2010.

Initial ignition experiments are expected to have yields in the range of tens of megajoules. Various options including 0.53-um operation and fast ignition have potential for demonstration of yields of $100 \mathrm{MJ}$ or greater. This breakthrough capability will have major impacts on national security and the realization of fusion as a clean energy source for the future. NIF's ability to access extreme pressures and temperatures will also open up new opportunities for discovery in astrophysics, condensed matter science, and other areas involving the study of matter at extreme conditions.

The completion of the National Ignition Facility as well as major upgrades to the the OMEGA laser (University of Rochester) and the Z-machine at Sandia National Laboratories will usher in the golden age of high-energy-density science in the United States. A truly exciting decade of discovery lies ahead.

\section{ACKNOWLEDGEMENTS}

The author acknowledges the hard work and contributions from the NIF Project and National Ignition Campaign teams, including colleagues at Los Alamos National Laboratory, Sandia National Laboratories, the University of Rochester Laboratory for Laser Energetics, and General Atomics, Inc. The author also acknowledges assistance from C. Keane in preparation of this manuscript. This work was performed under the auspices of the Lawrence Livermore National Security, LLC, (LLNS) under Contract No. DE-AC52-07NA27344. LLNL-PROC-403416.

\section{REFERENCES}

1. G. H. Miller, E. I. Moses, and C. R. Wuest, "The National Ignition Facility," Opt. Eng. 43, 2841-2853 (2004).

2. N. Fleurot, C. Cavailler, and J.L. Bourgade, "The Laser Megajoule (LMJ) Project dedicated to inertial confinement fusion: Development and construction status," Fusion Engineering and Design 74, 147-154 (2005).

3. National Ignition Campaign Execution Plan, LLNL report UCRL-AR-213718, NIF-0111975-AB, May 2006. 
4. C. A. Haynam et al., "National Ignition Facility laser performance status," Applied Optics, 46, 3276-3303, June 2007.

5. See the National Ignition Facility web site, http://www.llnl.gov/nif/.

6. J. D. Lindl, Inertial Confinement Fusion: The Quest for Ignition and Energy Gain Using Indirect Drive (Springer, 2998).

7. S. W. Haan et al., "Update on specifications for NIF ignition targets and their roll up into an error budget," Fusion Sci. Technol. 49 553-557 (2006).

8. M. Tabak et al., "Ignition and High Gain with Ultra-intense Lasers," Physics of Plasmas 1 (5), 1626-1634 (May 1994).

9. M. Tabak et al., "Fast Ignition," Physics of Plasmas 12, 057305 (2005).

10. National Research Council, "High Energy Density Physics: The X-Games of Contemporary Science," National Academies Press, Washington, DC, 2003.

11. National Task Force on High Energy Density Physics, "Frontiers for Discovery in High Energy Density Physics," Office of Science and Technology Policy, Washington, DC, 2004.

12. Interagency Task Force on High Energy Density Physics, "Report of the Interagency Task Force on High Energy Density Physics," National Science and Technology Council, Committee on Science, Office of Science and Technology Policy, Washington, DC, 2007. 